\title{
A PERCEPÇÃO DO ACOMPANHANTE NO PROCESSO DO NASCIMENTO
}

Adelita Deniporte Gonzalez ${ }^{1}$, Elizabete dos Santos Fernandes ${ }^{2}$, Elizangela Fasolo da Silva ${ }^{3}$, Marcelexandra Rabelo ${ }^{4}$, Silvana Regina Rossi Kissula Souza ${ }^{5}$

RESUMO: O nascimento é um período de transição fisiológica, e a Organização Mundial de Saúde recomenda ações humanizadas, dentre estas práticas está a presença do acompanhante durante o pré-natal, parto e puerpério, no Brasil esta prática é regulamentada por lei. Considerando a importância do apoio familiar, os benefícios do acompanhante para a gestante e a necessidade do cumprimento da lei, objetivamos conhecer a percepção do acompanhante no processo do nascimento. Trata-se de uma pesquisa descritiva com abordagem qualitativa, realizada em uma maternidade escola no período de novembro de 2009 à junho de 2010. A coleta de dados se deu por meio de entrevista semiestruturadas, transcritas e submetida à análise de conteúdo. Os resultados evidenciaram que os acompanhantes sentem-se satisfeitos e percebem a importância da sua inserção no processo do parto. Embora a presença do acompanhante ainda não seja uma realidade em todas as instituições de saúde, é relevante a preparação da equipe de saúde para receber a mulher e seu acompanhante. PALAVRAS-CHAVE: Parto humanizado; Direito constitucional; Acompanhantes de pacientes; Equipe de saúde.

\section{THE PERCEPTION OF THE COMPANION IN THE PROCESS OF CHILDBIRTH}

ABSTRACT: Childbirth is a period of physiological transition and the World Health Organization recommends humanized actions; among these practices is the presence of a companion during the prenatal check-up, birth and post-natal period. In Brazil, this practice is regulated by law. Considering the importance of family support, the benefits of the companion for the expectant mother and the need for complying with the law, the authors aimed to understand the perception of the companion in the process of childbirth. It is descriptive research with a qualitative approach, carried out in a teaching maternity unit in the period of November 2009 to June 2010. Data collection was carried out through semi-structured interviews, transcribed and submitted to content analysis. The results showed that the companions feel satisfied and notice the importance of their inclusion in the birth process. Although the presence of the companion is not yet a reality in all healthcare institutions, it is relevant to the preparation of the healthcare team to receive the woman and her companion. KEYWORDS: Humanized birth; Constitutional law; Patient companions; Health teams.

\section{LA PERCEPCIÓNO DEL ACOMPAÑANTE EN EL PROCESO DEL NACIMIENTO}

RESUMEN: El nacimiento es un periodo de transición fisiológica, y la Organización Mundial de Salud recomienda acciones humanizadas; de entre estas prácticas está la presencia del acompañante durante el prenatal, parto y puerperio; en Brasil esta práctica es reglamentada por ley. Considerando la importancia del apoyo familiar, los beneficios del acompañante para la gestante y la necesidad del cumplimiento de la ley; el objetivo de este trabajo fue conocer la percepción del acompañante en el proceso del nacimiento. Es una investigación descriptiva con abordaje cualitativa, realizada en una maternidad escuela en el periodo de noviembre de 2009 a junio de 2010. Los datos fueron recogidos por medio de entrevistas semi estructuradas, transcriptas y sometidas al análisis de contenido. Los resultados muestran que los acompañante se sienten satisfechos y perciben la importancia de su inserción en el proceso del parto. Mismo que la presencia del acompañante todavía no sea una realidad en todas las instituciones de salud, es relevante la preparación del equipo de salud para recibir la mujer y su acompañante. PALABRAS CLAVE: Parto humanizado; Derecho constitucional; Acompañantes de pacientes; Equipo de salud.

\footnotetext{
${ }^{1}$ Enfermeira Obstetra. Mestre em Tecnologia em Saúde. Professora do Programa de Pós-Graduação em Enfermagem da Pontifícia Universidade Católica do Paraná - PUC PR.

${ }^{2}$ Enfermeira Obstetra. Especialista em Neonatologia. Enfermeira da Prefeitura Municipal de Saúde de Curitiba-PR.

${ }^{3}$ Enfermeira Obstetra da Prefeitura Municipal de Curitiba-PR.

${ }^{4}$ Enfermeira Obstetra. Professora do Departamento de Enfermagem da Universidade Federal do Paraná - UFPR.

${ }^{5}$ Enfermeira Obstetra. Mestre em Engenharia de Produção. Doutoranda pelo Programa Interunidades de Enfermagem da Universidade de São Paulo. Professora do Curso de Graduação em Enfermagem da UFPR.
}

Autor correspondente:

Marcelexandra Rabelo

Universidade Federal do Paraná

R. Lothário Meissner, 632 Bloco Didático II - 80210-170-Curitiba-PR-Brasil

E-mail: marcelexandra@ig.com.br
Recebido: $13 / 01 / 2012$ Aprovado: 28/05/2012 


\section{INTRODUÇÃO}

Historicamente, o parto, atendido em domicílio por mulheres experientes, que inspiravam confiança e representavam o grupo social, adquiriu características femininas. No século XX, com o avanço da tecnologia, o parto passou a ser institucionalizado e medicalizado, adotando-se um modelo tecnicista de assistência, o qual tem como característica inúmeras intervenções sobre o corpo da grávida, passando de evento fisiológico à patológico ${ }^{(1)}$

A institucionalização do parto, associada às normas e rotinas hospitalares, ocasionaram às mulheres isolamento social e afastamento de seus familiares durante o trabalho de parto e parto, pois são internadas em ambientes coletivos e sem privacidade, são submetidas às rotinas e à passividade ${ }^{(2)}$. Neste cenário, a parturiente torna-se fragilizada, suscetível à experiências negativas, impedida de conduzir seu próprio parto de forma natural, pois o cumprimento de normas e rotinas acarretam procedimentos desnecessários, coagindo a mulher à submissão e à aceitação do que lhe é oferecido $^{(3)}$.

O processo de nascimento é um período de transição fisiológica e social marcante para a mulher, porém associado à sentimentos de ansiedade, alegria, tristeza e medo. Consiste em momento frágil e vulnerável, tornando imprescindível a participação do acompanhante no processo parturitivo ${ }^{(4-5)}$, ação esta que deve ser estimulada pela equipe responsável pelo cuidado, em cumprimento à Lei 11.108 de Abr de 2005. No entanto, para atender à legislação faz-se necessário um processo de reorganização dos serviços e da formação dos profissionais ${ }^{(6-7)}$.

Estudos comprovam inúmeros benefícios decorrentes do apoio à mulher no momento do parto. O acompanhante proporciona encorajamento e segurança à mulher, com isso há redução do tempo de trabalho de parto pela produção hormonal fisiológica do parto; gera sentimentos de satisfação, tranquilidade e felicidade. $\mathrm{O}$ simples fato de ter alguém de seu convívio neste momento torna a parturição uma experiência positiva, contribuindo para o fortalecimento do vínculo familiar ${ }^{(6)}$.

Há uma busca dos profissionais de saúde para promover a humanização do parto, e neste contexto, salienta-se que o nascimento deve ser acompanhando por profissionais capacitados, porém resgatando o modelo humanístico ${ }^{(8)}$. A humanização hoje é um assunto muito abordado no que tange à gestação, ao trabalho de parto e ao parto, e reconhecida como importante elemento pelo Ministério da Saúde (MS) e pela Organização Mundial de Saúde (OMS) para redução da mortalidade materno-infantil. Compreende a capacitação profissional e criação de programas, como o Programa Nacional de Humanização (PHPN) no Pré-Natal e Nascimento. Esse foi instituído em junho de 2000 de acordo com a Portaria n. 569/GM com o objetivo de resgatar a atenção obstétrica integrada, qualificada e humanizada de forma articulada entre estados, municípios e unidades de saúde; em suas diretrizes de práticas benéficas de atenção ao parto, entre outras recomendam a presença do acompanhante ${ }^{(9)}$. Neste contexto, a figura paterna é relevante e, para que haja sua aproximação, os serviços de saúde devem incluir os homens nas consultas de pré-natal, para que possam acompanhar cada etapa da gestação e, posteriormente, o nascimento ${ }^{(5)}$. Considerando a necessidade de reintegrar o apoio familiar, os benefícios do acompanhante para a gestante e o cumprimento da lei, é preconizado que os serviços do Sistema Único de Saúde - SUS, da rede própria ou conveniada, permitiam a presença de um acompanhante junto à parturiente, durante $o$ trabalho de parto, parto e pós-parto imediato.

Reconhecendo a importância do acompanhante junto à parturiente, consideramos relevante conhecer a percepção do acompanhante no processo do nascimento, sendo o objetivo desta pesquisa.

\section{MÉTODO}

Trata-se de uma pesquisa descritiva com abordagem qualitativa, desenvolvida em uma maternidade pública no Município de Curitiba - PR, no período de novembro de 2009 a junho de 2010. Foi utilizado como critério de inclusão dos participantes: serem acompanhantes que permaneceram com a parturiente durante o trabalho de parto e assistiram o nascimento de parto normal.

Os acompanhantes convidados a participar do estudo foram informados quanto ao objetivo e desenvolvimento da pesquisa e assinaram o Termo de Consentimento Livre e Esclarecimento. Para a coleta de dados utilizouse a entrevista semiestruturada; os depoimentos, com duração média de 15 minutos, foram gravados por meio eletrônico e transcritos. Após a transcrição, os conteúdos foram analisados de acordo com a técnica de Análise de Conteúdo temática de Bardin, que visa obter

[...] por procedimentos objetivos e sistemáticos [...] a inferência de conhecimentos relativos às condições de produção/recepção destas mensagens ${ }^{(10: 42)}$. 
A amostra foi constituída por 9 participantes e seu tamanho foi definido com base no critério de saturação das informações obtidas nas entrevistas. Cada participanterecebeu um codinome referente ao nome de uma pedra preciosa.

Foram respeitados todos os requisitos éticos de pesquisa, em acordo com a Resolução n. 196/96. O projeto foi apresentado ao Comitê de Ética em Pesquisa do Setor de Ciências da Saúde da Universidade Federal do Paraná, sendo aprovado em reunião realizada no dia 10 de julho de 2009, com registro CEP/SD n. 738.073.09.06.

\section{RESULTADOS}

Os sujeitos participantes do estudo tinham entre 19 e 43 anos de idade; um tinha o ensino fundamental completo, dois o ensino médio completo, cinco o ensino médio completo, e um dos entrevistados cursava o ensino superior. Entre os acompanhantes, 7 eram companheiros e duas eram mães de parturientes.

A análise temática resultou em quatro categorias, a seguir apresentadas:

\section{Sentimentos vivenciados}

Os sentimentos vivenciados relatados pelos participantes foram intensos e variados, expressos como experiência única e emocionante. Esses relataram sentir-se importantes por estarem junto com a parturiente, oferecendo apoio e incentivo:

A experiência, achei mágica. Estar ali, com a pessoa que você gosta, com um ser que está chegando, que é seu [...] você está ali passando um apoio, incentivo, isso achei legal. (Citrino)

Primeira vez que acompanho o parto, foi bem emocionante. (Quartzo)

Foi uma experiência bastante legal e única [...] emocionante, porque você está ali do lado da pessoa que você ama, vendo o nascimento do seu filho, nossa! (Opala)

Vejo que é um momento único [...] eu quis estar acompanhando. Vejo como um momento único prá gente e vi que era muito importante minha presença ali, dando apoio para ela. Foi muito bom! (Jaspe)

\section{Percepção do acompanhante diante da receptivi- dade do profissional de saúde}

Todos os entrevistados ficaram satisfeitos com a equipe do centro obstétrico, um dos entrevistados mencionou descontentamento com funcionários da recepção e segurança. Os acompanhantes foram influenciados positivamente pelos funcionários do centro obstétrico, se sentiram bem recebidos pela equipe e satisfeitos por presenciar a assistência à parturiente:

Achei que eles me ajudaram a incentivar a minha esposa, me receberam bem, falaram o que eu tinha e o que não tinha que fazer prá tentar ajudar. (Citrino)

A equipe ficou tranquila, eu também. Por ter feito o curso já tinha uma noção [...] eles [equipe] viram que eu estava calma também, eu não estava apavorada, sempre tentando ajudar. [...] achei que a equipe ficou tranquila comigo. (Ônix)

Eles [equipe] foram muito profissionais, acho que a minha presença não intimidou ninguém, muito pelo contrário, ajudou minha esposa na hora do parto. Eu vi que a equipe me recebeu muito bem. (Jaspe)

[...] não posso criticar uma equipe inteira, tem pessoas maravilhosas aqui dentro, mas teve três ou quatro que tratam você mal, da recepção e segurança. (Ônix)

\section{Percepção do acompanhante sobre sua participação no nascimento}

Sete participantes ficaram satisfeitos com o papel desempenhado, por terem realizado ações de apoio para que a parturiente ficasse tranquila e confiante. $\mathrm{Na}$ visão do acompanhante há sentimentos de satisfação e valorização deste momento, ao oferecer ajuda e fortalecer vínculos:

Acho que fui $100 \%$, pois ela ficou totalmente tranquila comigo ali. Não abandonei, fiquei todo momento, não fui embora. Ela precisava de mim, eu estava ali, mandava me chamar eu estava ali. [...] lógico, sofre um pouco, mas ao mesmo tempo, dá um alívio, dá segurança sabendo que tem alguém ali. (Ônix)

Eu estava em todo momento muito tranquilo [...]. Então, acho que consegui passar motivação prá ela, dando bastante força prá ela conseguir ter o nosso filho. (Berilo)

Percebe-se, contudo, que ainda faltam orientações 
dos profissionais para que o acompanhante se sinta incluído no processo:

Não tive um desempenho muito bom. Meu primeiro filho, então acho que não fui tão bom como deveria ser. Faltou orientação, não sabia exatamente o que eu tinha que fazer, fiquei meio perdido. (Opala)

\section{Importância do Curso de Preparo para o Parto no desempenho do acompanhante}

Dentre os sujeitos, quatro relataram ter participado do curso de preparo para o parto, oferecido gratuitamente pela maternidade em que o presente estudo foi desenvolvido. Este curso preparatório faz parte de Projeto de Extensão Universitária, do Curso de Graduação em Enfermagem da Universidade Federal do Paraná, ministrado por acadêmicas e professores com o objetivo de preparar gestantes e acompanhantes para o processo do nascimento.

Os acompanhantes entrevistados que participaram do curso demonstraram que as orientações recebidas foram fundamentais para diminuir a ansiedade e proporcionar segurança tanto para a mulher, quanto para seu acompanhante. Os demais participantes informaram que não fizeram cursos preparatórios, porém buscaram informações através da internet:

[...] a oficina abre a nossa visão, nosso entendimento. Nos faz entender que o parto não é um bicho de sete cabeças, te passa mais segurança. Participando da oficina eu pude ajudar melhor minha esposa. (Jaspe)

Recebemos orientação sobre o banhoterapia, o caminhar e o parto humanizado. No começo ela não queria parto normal, tinha na cabeça fazer cesárea, e a gente foi vendo todas aquelas vantagens. Coisas que eu já tinha visto na internet e com o curso eu consegui reforçar para ela mudar de ideia para o parto normal. $O$ curso nos preparou melhor para este momento. Achei que foi bom, contribuiu muito. (Diamante)

\section{DISCUSSÃO}

O nascimento é uma fase de transformação familiar e merece atenção especial, portanto, a presença do acompanhante é indispensável e deve ser vista de forma positiva para todos os membros envolvidos no nascimento. Para isso, é necessário qualidade de assistência e não somente o cumprimento das técnicas e rotinas. A atuação dos membros da equipe de saúde é de extrema importância, para a inserção, interação e orientação do acompanhante, fazendo com que este saiba desempenhar seu papel, bem como os benefícios da sua presença ${ }^{(11)}$.

A inserção do homem no nascimento permite delinear um novo papel para ele. Os pontos positivos vivenciados pelo acompanhante neste contexto estão relacionados à maior intimidade com a mulher, admiração pela força, sensação de orgulho e satisfação com a chegada do bebê, o que foi percebido pelos depoimentos dos pais.

O parto é um momento de intensas emoções e a participação do acompanhante, favorece contribuições no âmbito familiar ${ }^{(12)}$. Ressaltamos a importância do preparo da mulher e seu acompanhante para o processo do nascimento por meio de cursos ofertados por profissionais especializados, pois esta prática proporcionará tranquilidade e segurança para a vivência deste momento.

O hospital pode ser desconhecido e assustador para a mulher, acredita-se também que apenas uma visita à maternidade não é suficiente para possibilitar à mulher e ou/acompanhante familiarização com o local, desencadeando ainda insegurança e medo frente aos aconteci$\operatorname{mentos}^{(2)}$. No entanto, valorizar estas iniciativas beneficia a mulher, o acompanhante e o bebê. Nos depoimentos coletados e na literatura ${ }^{(2)}$, evidencia-se a importância da preparação para o processo de parto, além da necessidade do profissional oferecer informações claras e objetivas, criando desta maneira um vínculo de confiança com os envolvidos no processo, bem como valorizando seus próprios conhecimentos e experiências.

Preparar-se para um evento desconhecido envolto por mitos e crenças, é proporcionar aos envolvidos no processo a chance de vivenciar experiências positivas e renascedoras, pois sua presença fará deste um momento de integração familiar e contribui ainda para desmitificar e compreender as reais dimensões acerca do nascimento ${ }^{(2)}$, como pode ser constatado pelos depoimentos dos acompanhantes.

\section{CONSIDERAÇÕES FINAIS}

O nascimento é um evento mobilizador, do qual as pessoas desejam participar e estar presentes, independentemente do nível de escolaridade ou da faixa etária.

Acreditamos que a importância de informar com antecedência sobre o direito de acompanhar o parto reside na possibilidade do acompanhante se preparar psicologicamente para vivenciar este momento, de forma a maximizar os benefícios para todos: para si mesmo, a 
parturiente e a equipe de saúde. Uma preparação adequada dos pais traz maior compreensão do processo do parto e, consequentemente, maior segurança.

Da mesma forma, a ausência de informações não pode constituir impedimento para a vivência desta experiência já que os acompanhantes que não passaram por treinamento podem estar aptos a atender, pelo menos, à demanda de apoio às mulheres. O presente estudo revelou maior participação masculina no nascimento, fato este que demonstra o desejo do homem em inserir-se no contexto como parte integrante do processo, e não meramente como um espectador.

$\mathrm{O}$ pai da criança precisa ser visto como alguém que está vivenciando um momento especial; logo, ele também precisa ser acolhido. Isto, por certo, produzirá um sentimento de confiança e reconhecimento do seu papel, que refletirá positivamente no desenvolvimento de suas atividades. A presença do pai, considerada por alguns profissionais como um problema, pode se transformar numa oportunidade para que o serviço também se beneficie dessa presença. Para tanto, os profissionais devem interagir com o acompanhante e fornecer as orientações necessárias para que este atenda às expectativas da parturiente.

A presença do acompanhante no nascimento ainda não é uma realidade em todas as instituições de saúde. Entretanto, é relevante a preparação da equipe de saúde envolvida, para receber a mulher e acompanhante, compreendendo e aceitando como benéfico o nascimento acompanhado. Desta forma, os depoimentos levam à uma reflexão e salientem a importância do suporte familiar no nascimento.

\section{REFERÊNCIAS}

1. Motta CCL, Crepaldi MA. O pai no parto e apoio emocional: perspectiva da parturiente. Paidéia. 2005;15(30):105-8.

2. Bruggmann OM, Parpinelli MA, Osis MJD. Evidências sobre o suporte durante o trabalho de parto/parto: uma revisão da literatura. Cad. Saúde Pública. [Internet] 2005;21(5) [acesso em 10 jun 2010]. Disponível: www. scielo.br/pdf/csp/v21n5/03.

3. Frello AT, Carraro TE. Componentes do cuidado de enfermagem no processo de parto. Rev. Eletr. Enf. [Internet] 2010;12(4) [acesso em 10 jun 2010]. Disponível: www.fen.ufg.br/revista/v12/n4/v12n4a10.

4. Perdomini FRI, Bonilha ALL. A participação do pai como acompanhante da mulher no parto. Texto Contexto Enferm. 2011;20(3):245-52.
5. Ministério da Saúde (BR). Humaniza SUS: visita aberta e direito a acompanhante. Série B. Textos básicos de saúde. Brasília; 2009.

6. Bruggmann OM, Osis MJD, Parpinelli MA. Apoio no nascimento: percepções de profissionais e acompanhantes escolhidos pela mulher. Rev. Saúde Pública. 2007;41(1):44-52.

7. Longo CSM, Andraus LMS, Barbosa MA. Participação do acompanhante na humanização do parto e sua relação com a equipe de saúde. Rev. Eletr. Enf. [Internet] 2010;12(2) [acesso em 14 jul 2010]. Disponível: http:// www.fen.ufg.br/fen_revista/v12/n2/pdf/v12n2a25.pdf

8. Domingues RMSM, Santos EM, Leal MC. Aspectos da satisfação das mulheres com a assistência ao parto: contribuições para o debate. Cad. Saúde Pública. 2004; 20(1):52-62.

9. Ministério da Saúde (BR). Programa de humanização do Parto: humanização no pré - natal e nascimento. Brasília; 2002.

10. Bardin L. Análise de conteúdo. Portugal: Edições 70; 2009.

11. Alexandre AMC, Martins MA. Vivência do pai em relação ao trabalho de parto e parto. Cogitare enferm. 2009;14(2):324-31.

12. Tomeleri KR, Pieri FM, Violin MR, Marcon SS. Eu vi meu filho nascer: vivência dos pais na sala de parto. Rev. Gaúcha enferm. 2007;28(4):497-504. 